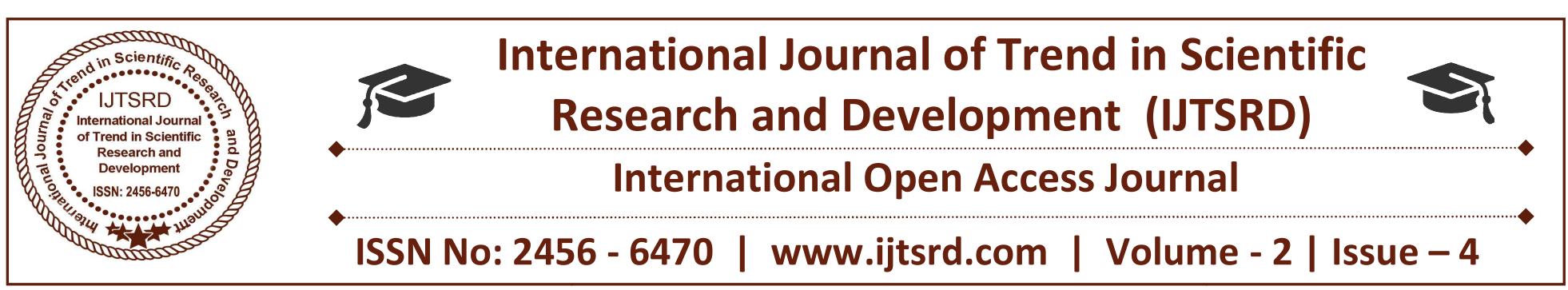

\title{
An Insight into Cloud Computing Paradigm and Services
}

\author{
Heena Girdher ${ }^{1}$, Jagjit Kaur ${ }^{2}$ \\ ${ }^{1}$ Department of Computer Applications, ${ }^{2}$ Department of Computer Science and Engineering \\ Chandigarh Group of Colleges, Landran, Mohali, Punjab, India
}

\begin{abstract}
Cloud computing is a computing model which provides the computing services over the internet on pay-as-you-go basis. You can take the services on rent instead of building your own IT- infrastructure which results in cost saving. In this paper, we have discussed the differences between traditional IT infrastructure and cloud computing. We have also discussed the benefits of cloud, risks associated with cloud computing and the cloud models.
\end{abstract}

Keywords: Cloud computing, Iaas, I Saas, P Paas, Virtualization

\section{INTRODUCTION}

Cloud computing is the delivery of computing services like servers, storage, applications, databases, networks and so on anywhere, anytime over the internet. The services are provided by cloud service providers on pay-as-you-go basis. You have to pay only for the amount of services you use.

Why cloud Traditional software applications require in-house building and deploying of complex IT infrastructure. A team of professionals is required to manage this infrastructure. Hardware are prone to be updated very soon. Managing software installations and up gradations is a challenging task. To manage infrastructure is not an easy task. To run small business, you have to spend a lot of money on infrastructure. Cloud computing provide services on rent just like electricity. You use electricity rather than building it.

Traditional applications require capacity planning before using the application. We buy more servers so that at peak time they can meet our demands but at other times our servers will be idle. Suppose if we talk about online shopping site, we know that during festival days there will be more users of the site. So our site should be able to handle that load also. In cloud computing, our application may scale up or down elastically. There is no need to do capacity planning in advance. We can rent more servers based upon usage.

\section{BENEFITS OF CLOUD}

There are three main benefits of cloud:-

Cost: - cloud provides services at low cost than building your own IT infrastructure. In cloud, you have to pay only for the amount of services you use.

Self-service:- With cloud, you can get the services with just few clicks. You don't have to be depend upon others for services.

Elasticity: -With the help of cloud, services can be scaled up or down on demand.

\section{RISKS IN CLOUD COMPUTING}

There are various risks associated with cloud computing:-

Security: - In cloud computing, our data and applications are managed by third party but it is the higher risk to give control of your data to third party.

Data Location: - In cloud, we don't know the location of data. We don't know at which location our data is placed on the server.

There are security benefits of cloud also. In cloud, multiple copies of data is placed at many places. In the case of failure, data can be easily recovered. 


\section{CLOUD MODELS}

There are two types of cloud models i.e.service models and deployment models.

Cloud service models are divided into three categories Iaas, Paas and Saas.

Iaas: -In infrastructure as a service, we can take infrastructure like servers, storage, databases on rent from cloud service providers. Virtualization is the process through which we can access remote servers. AWS provide Amazon EC2 to use infrastructure as a service. In Iaas you can use the remote servers without worrying about the hardware maintenance.
Paas: -In platform as a service, we can take the platform on rent from service providers. Suppose if a student writes a first java program and he has not installed JVM on his machine. He can directly copy the java code and run the code online by using online java compiler. Paas is used by developers to develop, test and deploy software applications.

Saas:-In software as a service, we can use the software online without purchasing the license of software and installing it on computer. In saas, software upgrades and security patching is managed by the service providers. In saas, users do not have their own software. They are using the company software. Gmail is the example of saas where Gmail is the software and Google is the service provider.

\section{Table 4.1: Cloud Service Models}

\begin{tabular}{|c|c|c|c|}
\hline Services & Use & Users & Examples \\
\hline Iaas & $\begin{array}{l}\text { Outsource } \\
\text { elements }\end{array}$ & $\begin{array}{l}\text { Network } \\
\text { architects }\end{array}$ & $\begin{array}{l}\text { IBM SoftLayer, } \\
\text { Amazon EC2, } \\
\text { Rackspace }\end{array}$ \\
\hline Paas & $\begin{array}{l}\text { Here, the platform used to } \\
\text { design, develop, build and } \\
\text { test applications se are } \\
\text { provided by the cloud } \\
\text { infrastructure. Develo }\end{array}$ & $\begin{array}{l}\text { Application } \\
\text { developers } \\
\text { h and }\end{array}$ & $\begin{array}{l}\text { IBM BlueMix, } \\
\text { Microsoft Azure, } \\
\text { Cloudbees } \\
\end{array}$ \\
\hline Saas & $\begin{array}{l}\text { A software distribution } \\
\text { model in which a third- } \\
\text { party provider hosts } \\
\text { applications and make them } \\
\text { available to customers over } \\
\text { the internet. }\end{array}$ & $\begin{array}{l}\text { End users } \\
-6470\end{array}$ & $\begin{array}{l}\text { SendGrid, Tivoli } \\
\text { Live, } \\
\text { Salesforce.com }\end{array}$ \\
\hline
\end{tabular}

\section{DEPLOYMENT MODEL}

Public cloud: -It is available to the general public. It provides the sharable storage. Example: - Google drive.

Private cloud: - It is available to an organization. It provides the dedicated storage to an organization. If an organization doesn't want to put its crucial data on public cloud, it can hire private cloud. Private clouds can be deployed at company's own data centres or on the third party.
Hybrid cloud: -It is the combination of both public and private cloud. Suppose ABC institute puts its crucial lecture videos in a private cloud but it replies to its students via email using public cloud, is an example of hybrid cloud.

Community cloud: -Community cloud is used by number of organizations. Multiple organizations purchase the sharable storage from service providers is an example of community cloud. 


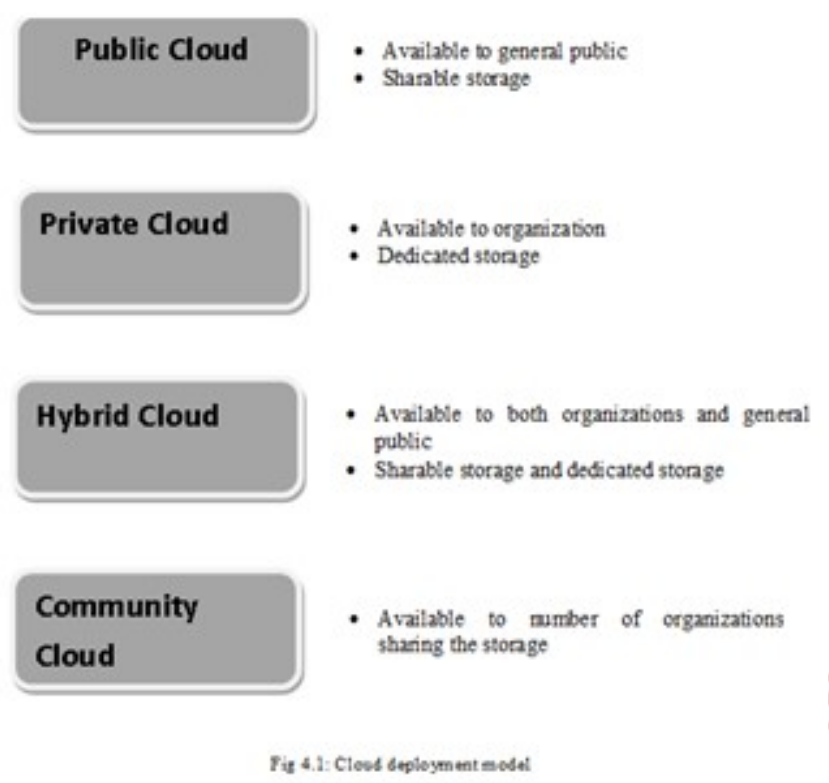

To understand the concept of cloud, let us take an example. Suppose you want to open an E-commerce company and you have to manage sales, marketing department and IT infrastructure but you have limited amount of money. In this case you want someone to manage your infrastructure so that you may focus on other departments. It is possible through cloud computing.

\section{CONCLUSION}

In this paper, we have discussed the concept of cloud computing which has gained lot of popularity now a days. Organizations are moving their data to cloud due to its various benefits over traditional IT infrastructure. But there is security issues related to cloud also. So there is a need to focus on the security problems to maintain the trust level of the organization

\section{REFERENCES}

1. Onur, E., Sfakianakis, E., Papagianni, C., Karagiannis, G., Kontos, T., Niemegeers, I., Chochliouros, I.P., de Groot, S.H., Sjodin, P., Hidell, M., Cinkler, T., Maliosz, M., Kaklamani, D.I., Carapinha, J., Belesioti, M., Fytros, E., -Intelligent End-To-End Resource Virtualization Using Service Oriented Architecturell, Delft Univ. of Technol., Delft, Netherlands, GLOBECOM Workshops, IEEE, 28 December 2009.

2. Buyya R, "Market-Oriented Cloud Computing: Vision, Hype, and Reality of Delivering Computing as the 5th Utility," 9th IEEE/ACM International Symposium on Cluster Computing and the Grid, pp. 1, 2009.
3. G. Gruman, "What cloud computing really means", InfoWorld, Jan. 2009.

4. R. Buyya, Y. S. Chee, and V. Srikumar, -Market-Oriented Cloud Computing: Vision, Hype, and Reality for Delivering IT Services as Computing Utilitiesll, Department of Computer Science and Software Engineering, University of Melbourne, Australia, pp. 9, July 2008.

5. C. Braun, M. Kunze, J. Nimis, and S. Tai. -Cloud Computing, Web-based Dynamic ITServices". Springer Verlag, Berlin, Heidelberg, 2010.

6. S. Adabala, V. Chadha, P. Chawla, R. Figueiredo, J. Fortes, I. Krsul, A. Matsunaga, M. Tsugawa, J. Zhang, Mi. Zhao, L. Zhu, and X. Zhu. From virtualized resources to virtual computing Grids: the In-VIGO system. Future Generation Comp. Syst., 21(6):896-909, 2005.

7. P. Barham, B. Dragovic, K. Fraser, S. Hand, T. L. Harris, A. Ho, R. Neugebauer, I. Pratt, and A. Warfield. Xen and the art of virtualization. In Proceedings of the 19th ACM Symposium on Operating Systems Principles, pages 164-177, NewYork, U. S. A., Oct.2003 